\title{
ANALYZING THE EFFICIENCY OF BANK BRANCHES $V I A$ NOVEL WEIGHTED STOCHASTIC IMPRECISE DATA ENVELOPMENT ANALYSIS
}

\author{
NEZIR AYdin AND GÖKHAN YURDAKUL*
}

\begin{abstract}
As of 21st century, the terms of efficiency and productivity have become notions which dwells on both business and academic world more frequently compared to past. It is known that it is hard to increase the efficiency and productivity of both production and service systems. In this study, the efficiency analysis of the branches of a bank was conducted. Furthermore, a Weighted Stochastic Imprecise Data Envelopment Analysis (WSIDEA), which is a new approach developed based on Data Envelopment Analysis (DEA), was proposed. Efficiency levels and results of decision-making units were examined according to the proposed new method. Additionally, six different DEA model results are obtained. The results of the six different DEA model and the proposed "WSIDEA" model were compared in terms of efficiency level of decision-making units, and the differences between them were examined. Sensitivity of the inefficient units were also examined. On the other hand, unrealistic efficiency levels created by traditional methods for branches were also analyzed. Apart from all these sensitivity analyses, the sensitivity of the data set used in the analysis is scrutinized.
\end{abstract}

Mathematics Subject Classification. 90C08.

Received August 6, 2020. Accepted April 20, 2021.

\section{INTRODUCTION}

The banking is a major sector affecting the entire economy, as well as being the most important element of the Turkish financial system. Furthermore, the banking sector is a key part of the financial system that mediates resource transfer in the economy. The relative share of the banking sector in the financial system may differ in each country depending on the level of economic and social developments. Even though the banking sector share in the financial system has reducesis in the financial system its share still has a very high level in Turkey [19]. Therefore, banking sector in Turkey is one of the main elements of the country's financial system. This causes because of that the non-banking intermediaries are not sufficiently developed as banking system. Furthermore, banking system is of crucial importance in terms of the operation of the economy, collecting the savings of people and allocating these resources to the sections to be used [58].

Although the overall global and local uncertainties remain high in 2018, the banking sector in Turkey has continued to grow with the impact of the rise in exchange rates. As of the end of the third quarter of 2018, the asset size of the sector exceeded 4.209 billion $€$ (with an increase of $37.9 €$ ). In the same period, the total loan

Keywords. Data Envelopment Analysis, Banking, Weighted Stochastic Imprecise Data Envelopment Analysis, Sensitivity Analysis.

Department of Industrial Engineering, The Yildiz Technical University, Istanbul, Turkey.

*Corresponding author: gokhanyurdakul25@gmail.com, f0619018@std.yildiz.edu.tr 
volume of the sector expanded by $29.8 \%$ annually and reached 2.588 billion $€$, while the securities of the banks increased by $30 \%$ to 490 billion $€$. In the first nine months, own resources increased by $18.3 \%$ and reached 408 billion $€$, while net profit increased by $11.1 \%$ to 41 billion $€$ [32].

In today's global world, with the rapid developments in technology the competition is rising accelerately especially in the banking sector. Within this competitive environment in the business world as well as in the non-profit service sector, the measurement and analysis of performances and events are crucial for all sectors that prioritize efficiency. Therefore, evaluating the financial performance of all elements within a system/company became even more important. Consequently, the concepts of productivity, efficiency and effectiveness are frequently emphasized. Numerous parametric and nonparametric models are used in the literature to analyze the performance levels of decision-making units (DMU) [21,52]. Data Envelopment Analysis (DEA) is one of the non-parametric approaches used in the literature to measure the efficiency with respect to available inputs and outputs [30].

DEA is a model for measuring the relative efficiency of similar DMU using the same input or output at different rates or in different amounts [30], and it is used since 1970s for analyzing efficiency of the systems [15]. The DEA model first introduced by Charnes et al. [11], and it is called the CCR-the initials of the authors. Later, the BCC model was proposed by Banker et al. [5]. In addition to the fact that there has been a large number of studies using traditional DEA-CCR models, numerous studies with different DEA models have recently been introduced in the literature [35], especially in the last decade. Besides, it is possible to come across with hybrid models (AHP-DEA, DEA-SMAA - Stochastic Multicriteria Acceptability Analysis - etc.) in which DEA is integrated with other techniques [38]. In this context, an important question arises; for what dataset, which DEA model should be used or which DEA model works better.

One of the important discussions in the literature is how accurately DEA models conduct efficiency analyses. This is due to some handicaps that DEA models face with. Some of these handicaps are; which DEA model will be used in the analysis, which path to follow in determining the input and output classes when creating the data set, and which values the decision variables take. Moreover, whether the model or data set are deterministic or stochastic are other problems that are faced with. Another issue is when the analysis result is equal to 1 , the relevant DMU is considered as fully efficient. If the score is less than 1 then the relevant DMU is not considered as fully efficient. While in some cases, it can be considered as fully efficient even the score is less than 1, i.e. 0.9. Finally, the expert opinion is not included in the traditional DEA structure. According to some researchers, this poses a problem [37].

In the literature are valuable in their own way because each provides a solution toward different problems. The main motivation of this study is to get rid of the artificial efficiency levels of DMUs with a holistic model proposal and to analyze the real efficiency levels of DMUs. The Weighted Stochastic Imprecise Data Envelopment Analysis (WSIDEA) model suggested in this study is an integrative model, unlike other models in the literature. In addition, the WSIDEA model provides solutions to more than one problem at the same time: assigning a value of zero to some variables, considering stochastic data and assigning different importance levels to data. WSIDEA model answers all these issues and provides more accurate results. Although several DEA models suggested and a wide range of application areas are studied the WSIDEA model proposed in this study is different from all existing models in three points; Firstly, WSIDEA model is a stochastic type of model, which enables using both deterministic and stochastic data in the model. In this respect, WSIDEA enables not only analyzing the current state but also future state of the DMUs. Secondly, in traditional DEA models, many variables may take the zero-value. However, in the WSIDEA model, all variables are recovered from zero. Thus, the effects of all variables are considered in the analysis. This ensures a more accurate and consistent efficient results. Thirdly, in traditional DEA models, the importance level of all data is considered equal, which is actually not applicable in real cases because the importance of all data is not the same for decision makers. Contrarily, WSIDEA model enables the decision maker to determine the importance level of the data through experts' opinions and consider them differently. This is a very important feature because such circumstances cause several problems: First, some data may be more important than others for researchers or DMU managers. For example, for a retail apparel company, the amount of turnover may be more important than the number of products, or the monthly total 
cost may be more important than the number of personnel. The same is true for the banking sector. Mansour and Moussawi [36] said that the size of the bank has a positive effect on bank efficiency. However, in the same study, it is said that the population indicators also have a negative effect on efficiency level. Grigorian and Manole [25] stated that bank productivity is positively correlated with income per capita. Based on these two examples, handling these data in the same way as in DEA-based models prevents reaching an accurate level of efficiency. In this respect, the influence level of each data used in the analysis should be taken differently. In the WSIDEA model, this issue is handled by taking the expert opinions and integrating into the model. Considering these three features, we think that the WSIDEA model provides more accurate efficacy analysis results compared to other DEA-based models in the literature.

Considering above mentioned arguments, it is an undeniable fact that a complementary DEA-based hybrid model should eliminate all these problems. For this reason, in this study, an integrated DEA-based model is proposed to handle all these issues.

Thus, the aim of this study is to analyze the efficiency of different branches of a bank with a novel DEA based approach, which is newly introduced in this study. The rest of the study is organized as follows: The second section reviews the studies conducted with DEA in the literature. In the third section, the aim, used approaches, conventinal DEA, imprecise and stochastic DEA are introduced and the analyses of these model are presented. At this point, we need to underline that the main reason why we call the model developed by Cook and Zhu [15] as imprecise DEA is because there are flexible data sets that are not certain whether the some of data set is input or output. For this reason, we call this model an imprecise DEA model. If the data to be used in the analysis itself is uncertain, the model becomes different than their model. Than, the model proposed by Toloo [47] and Toloo et al. [49] need to be considered. In the fourth section, the proposed model is presented and a real case study is conducted with the sensitivity analysis. Also, the results and discussions are provided in this section. The last section presents the conclusions and future directions.

\section{LitretURE REVIEW}

Several different studies in the literature regarding DEA, which has been studied by researchers in a wide range of applications over the last thirty years, are presented. These studies have been conducted in several different fields ranging from banking to hotel management and from financial markets to service sectors. In addition to classical DEA, it has recently been strengthen with different models, and consequently different versions are introduced such as stochastic DEA [44], imprecise DEA systems [15], two-stage DEA [13], fuzzy DEA [26], and other integrated applications i.e., DEA-AHP - Analytic Hierarchy Process - [53], DEA-Topsis (Techinque For Order Preference By Similarity to an Ideal Solution) [59].

Land et al. [33] was one of the first to propose the chance-constrained based DEA. They showed how DEA model behaves when stochastic input and output are used. Emphasizing that the deterministic DEA is simpler than the stochastic DEA, the distribution of data in stochastic DEA need to be known, and that the model they propose is more suitable for real life problems [33]. In another study, Sueyoshi [44] have made an efficiency analysis of Japan Petrolium companies with stochastic DEA. In their study, they showed that using deterministic inputs and stochastic outputs while the risk criterion and expected efficiency values ( $\alpha$ and $\beta$, respectively) increase the efficiency values of DMUs increases [44]. As another type of stochasticity, chance-constrained DEA is applied by Cooper et al. [16]. They discussed the equivalency of deterministic models to stochastic DEA models [16]. Later, Talluri et al. [46] also used a chance-constrained DEA to examine the uncertainty in multiple performance criteria vendor selection/assessment problem. By their application in a pharmaceutical company, they showed that chance-constrained DEA was more useful than the classical DEA [46].

In their study, Amin and Toloo [1] wanted to determine the most efficient DMUs in DEA with a linear model that was run once with common inputs. Compared to the proposed DEA-based approaches that have been used to find the most efficient DMUs, this integrated DEA model allows models to calculate the efficiency scores of all DMUs with a single formulation, where a common set of weights are used for all DMUs. On the other hand, the model proposed in this study identifies the most efficient units using less formulations comparing to similar 
DEA models. Finally, Amin and Toloo [1] suggested that the trial and error method which is proposed by Ertay et al. [23], should not be used to determine the most efficient [1] units.

Further, Cook and Zhu [15] proposed Indefinite Data Envelopment Analysis (IDEA) model to solve the problem of defining input-output categories in DEA. Their successful application helped researchers to easily categorize data as either input or output [15]. Stochasticity searches in DEA continued by Kao and Hwang [29]'s study in which they proposed a two-stage DEA model. In the model, they divided the production process into two sub-processes. In the first process, $x$ defined as the input and $z$ as the output and the input of the second process $y$ becomes the output of the last process. The total efficacy is obtained by multiplying the efficacy measures of the two sub-processes established [29].

To provide different applications of DEA; Boscá et al. [8] studied the technical performance analysis of Italian and Spanish league professional footballers. In the study, they performed two different analyzes, offensive and defensive, and evaluated the efficiency analysis of the leagues as two categories [8]. Simultaneously, Cooper et al. [17] conducted the activity analysis of basketball players with DEA. In suggesting a new model with non-zero weight selection, DEA was shown to be more advantageous than the ABC index [17]. Paralelly, Lewis et al. [34] conducted an analysis in American baseball league activities conducted between 1901 and 2002 with DEA. They analyzed three different efficacy scores and stated that W-efficiency values were significantly more important [34] than others. In their study, Talluri and Yoon [45] stated that decision-makers are included in DEA method thanks to weight restricted DEA models [45]. Bian and Yang [6] analyzed the environmental and resource activities of the Chinese provinces using a Shannon's entropy-based DEA model. Researchers analyzed 30 different states with six different models, then weighted the results found by Shannon's entropy and determined which states were actually effective [6].

Usually, when the data are stochastic, chance-constrainted approach is preferred as in Atalay and Apaydin [3]. They examined the variation in results when the distributions of input/output data change [3]. Also, Azadi and Saen [4] presented a new chance-constrained DEA approach and applied in the 3rd party reverse logistics applications [4]. In their study Hsiao et al. [27], proposed a different model, which integrates Russell weighted measurement technique with entropy-based weighting. The advantages of the proposed model over the Russell measurement technique can be summarized as follows: First, it eliminates the problem of equal weight effect in the Russell measurement technique. Second, it incorporates all advantages of the Russell measurement technique. Third, it has simpler operations than other Russell-based models. They showed the efficiency of the proposed model by applying it to Taiwan's commercial banks [27]. In their study, Toloo and Nalchigary proposed a new integrated DEA model to find the most efficient supplier with imprecise data. While the model proposed in the study enables the use of cardinal and ordinal data together, they stated that the new integrated DEA model yielded better results than Farzipoor Saen's [24] study. As a result, a method has been developed to rank suppliers using this model [48].

$\mathrm{Wu}$ et al. [57] reinterpreted the cross-efficiency evaluation model used as one of the DEA models using Shannon's entropy and called the "final average cross-efficiency evaluation" [57]. Demireli and Özdemir [22] carried out an activity analysis that showed the macroeconomic performances of 13 European countries. They found that there were statistically significant differences between the deterministic model and the stochastic model [22]. Chitnis and Vaidya [14] evaluated the performance of tennis players. In the study, they performed an activity analysis of 40 different tennis players with a holistic multidimensional approach and showed that 22 players were fully efficient and 18 were not fully efficient [14]. In another study, Olesen and Petersen [38] examined DEA and its extensions [38]. Ross et al. [39] presented a new approach for supplier evaluations. Suppliers' performance evaluations were performed with chance-limited DEA. He used inputs as deterministic and outputs as stochastic [39].

In their study, Tunca and Deliktaş [51] analysed the agricultural efficiency measurement of OECD countries by dynamic DEA. According to the results obtained from the Dynamic DEA, Belgium-Luxembourg, Netherlands, Italy and New Zealand are selected as the most effective countries among the OECD countries. When the static general activity scores, which are the static part of the overall activity resulting from the inefficient use of variable inputs, are examined it was seen that Austria, Iceland, Japan, Korea, Switzerland and the USA 
are active countries [51]. Rubem and Brandao [40] analyzed the efficiency of UEFA EURO 2012 for national teams with BCC DEA and multi-purpose Linear Programming (LP). At the end of the study, only Greece and Italy were determined as active, while the other teams remained below the activity limit. The efficiency ratio of the champion of the tournament was 94\% [40]. Soleimani-Damaneh and Zarepisheh [43] also presented a new approach based on Shannon's entropy in their study on this issue. In their study, five different DEA models were used to analyze the efficiency of 20 universities. Afterwards, the results were weighted by Shannon's entropy and analyzed the actual ranking levels of DMUs [43]. According to Mecit and Alp [37], the flexibility of the weights in the classical DEA models causes some important inputs and outputs to take zero value. On the contrary, a data group which is less important than others according to the decision maker, may have a very high weight value [37]. Shuai and $\mathrm{Wu}$ [42] conducted a DEA-based model of event analysis for tourist hotels in Taiwan. In the study, they analyzed how the tools on the web sites reflect in hotel performances with gray entropy [42].

As mentioned above, the efficiency levels of DMU may vary according to the model and the data set used. On the other hand, in the models other than weighted constrained models, the decision variables $u_{r}$ and $v_{i}$ of the inputs and outputs are assigned by the model. In fact, the conventional models accept the effect of each data group equally. However, according to experts, the situation leads to erroneous results because some data groups used in the model may be more important or insignificant than others. Moreover, a value of zero may be assigned to a data that may be very important for the respective DMU, while a data set of less importance can be assigned a high weight. This means that the relevant data is not included in the activity calculation or the impact of unnecessary data is increased, which may be incorrect if we speak of a full level of efficiency.

\section{RESEARCH METHOD}

Although there are basically two models such as CCR and BCC introduced in the literature, it is possible to come across a vast number of studies and models of DEA. Each above mentioned study is valuable and it is not possible to say for sure which model is superior to another. Even though these approaches are basically the same, they differ by the way they perform efficiency analysis in which some considers the ratio, while others consider the scales. Further, the results differ when different DEA models are applied even to the same problem. Thus, the choice of the model to be applied to the problem or the data gup ahand is also questioned by the researchers. This situation is still being investigated by many scientists. Soleimani-Damaneh and Zarepisheh [43] also presented a new approach based on Shannon's entropy to investigate this issue. In their study, five different DEA models were used to analyze the efficiency of 20 universities. Afterwards, the results were weighted with Shannon entropy, and the actual ranking levels of DMUs are analyzed [43].

In this study, different than the models in the literature, a new integrated DEA model was proposed. The proposed model is constructed based on two basic models. One of these is imprecise DEA, the model proposed by Cook and Zhu [15], and the future DEA model, which is proposed by Sueyoshi [44]. Later, the proposed model's results were compared with the results of six DEA models. Models to be discussed in this study can be examined in four categories; classical DEA approaches (CCR, BCC), Weigted Restricted DEA, Imprecise DEA (IDEA) and stochastic DEA (SDEA) models. Four input sets and four output sets were selected for each DEA model in the analysis. The inputs a Personnel Expenses, Branch Size of the Area $\left(\mathrm{m}^{2}\right)$, Rent Expenses and the Number of Staff. The outputs are Business Card Rurnover, Banking Service Revenue, Credit Card Turnover and Cash Loan Revenues. All the traditional basic DEA models, IDEA, chanceconstrained DEA and weight constrained models were used in the analysis.

\subsection{Data Envelopment Analysis}

DEA is a non-parametric technique, which is constructed based on LP. Because of this feature, DEA is an easy and convenient way to process multiple inputs and outputs simultaneously. DEA aims to measure the relative performance of decision-making in situations where it is difficult to compare inputs and outputs with multiple and different scales or with different measurement units [30]. The basic CCR model was constructed 
as follows:

$$
\begin{aligned}
& \operatorname{Max} Z_{0}=\sum_{r}^{S} u_{r} y_{r 0} \\
& \text { s.t. } \\
& \sum_{i}^{M} v_{i} x_{i 0}=1 \\
& \sum_{r}^{S} u_{r} y_{r j}-\sum_{i}^{M} v_{i} x_{i j} \leq 0 \\
& v_{i} \geq 0 \\
& u_{r} \geq 0
\end{aligned}
$$

There are two different data sets. The first one is the input set and the second one is the output set which are signed as $M$ and $S$, respectively. The indices " $i$ " and " $r$ " show the sets of $M$ and $R$, respectively. After that, $u_{r}$. and $v_{i}$. are the variables of the model. $x_{i}$ and $y_{r}$ show the $i$ th input and $r$ th output of the model, respectively.

\subsection{Imprecise Data Envelopment Analysis}

The creation of the input and output sets in traditional DEA models is entirely at the discretion of the user. Any data set can be included in the data group according to a user, while it can be included in the output group according to other users. Even this case by itself cause a big change in the activity scores. Regarding the situation, Cook and Zhu [15] proposed an uncertain DEA model [15]:

$$
\begin{aligned}
& \operatorname{Max} Z_{0}=\sum_{r}^{S} u_{r} y_{r 0}+\sum_{l}^{L} d_{l} \gamma_{l} w_{l 0} \\
& \text { s.t. } \\
& \sum_{i}^{M} v_{i} x_{i 0}-\sum_{l}^{L}\left(1-d_{l}\right) \gamma_{l} w_{l 0}=1 \\
& \sum_{r}^{s} u_{r} y_{r j}+\sum_{i}^{L} d_{l} \gamma_{l} w_{l j}-\sum_{i}^{M} v_{i} x_{i j}-\sum_{l}^{L}\left(1-d_{1}\right) \gamma_{l} W_{l j} \leq 0 \\
& v_{i} \geq 0 \\
& u_{r} \geq 0 \\
& \gamma_{l} \geq 0 \\
& d_{l} \in(0,1) . \\
&
\end{aligned}
$$

$\mu_{r}, v_{i}, \gamma_{l}$ represent the weights of the outputs, inputs and the flexible data set, respectively. Besides, another binary decision variable $d_{l}\{0,1\}$ determines which flexible data set will be included. If $d=1$, the related flexible variable is included in the output group, and when $d=0$, it functions as an input. However, as seen in equations (3.6)-(3.8), this model is a non-linear model because of the multiplication of two decision variables. Therefore, deterministic equivalence of the model should be developed. For this reason, Cook and Zhu [15] have proposed the following transformation:

$$
\begin{array}{rlrl}
\delta_{l} & =d_{l} \gamma_{l} & l & =1,2, \ldots, L \\
0 & \leq \delta_{l} \leq M d_{l} & l & =1,2, \ldots, L
\end{array}
$$




$$
\delta_{l} \leq \gamma_{l} \leq \delta_{l}+M\left(1-d_{l}\right) \quad l=1,2, \ldots, L
$$

Here $M$ is a large number. The final version of the model after the above conversion is as follows:

$$
\begin{aligned}
& \operatorname{Max} Z_{0}=\sum_{r}^{S} u_{r} y_{r 0}+\sum_{l}^{L} d_{l} \gamma_{l} w_{l 0} \\
& \text { s.t. } \\
& \sum_{i}^{M} v_{i} x_{i 0}-\sum_{l}^{L}\left(1-d_{l}\right) \gamma_{l} w_{l 0}=1 \\
& \sum_{r}^{S} u_{r} y_{r j}+\sum_{l}^{L} d_{l} \gamma_{l} w_{l j}-\sum_{i}^{M} v_{i} x_{i j}-\sum_{l}^{L}\left(1-d_{l}\right) \gamma_{l} w_{l j} \leq 0 \\
& v_{i} \geq 0 \\
& u_{r} \geq 0 \\
& \gamma_{l} \geq 0 \\
& d_{l} \in(0,1) \\
& \delta_{l}=d_{l} \gamma_{l} \\
& 0 \leq \delta_{l} \leq M d_{l} \\
& \delta_{l} \leq \gamma_{l} \leq \delta_{l}+M\left(1-d_{l}\right) .
\end{aligned}
$$

\subsection{Stochastic Data Envelopment Analysis}

Deterministic DEA models are based on the accuracy of all data, in which they work when the data is deterministic. However, in some cases data may be incomplete or contain uncertainties. For this reason, Charnes and Cooper [10] proposed a chance-constrained DEA model [10]. Through the chance-constrained DEA model uncertainty in the parameters can be included in the model.

Sueyoshi [44] stated that the future analysis was more important than today and suggested a new model based on chance-constrained DEA. In the proposed model, the input set was deterministic and the output set was stochastic. He named the proposed model "Future DEA model" [44]:

$$
\begin{aligned}
& \operatorname{Max}=\sum_{r=1}^{S} u_{r} \bar{y}_{r 0} \\
& \text { s.t. } \\
& \sum_{i=1}^{M} v_{i} x_{i}=1 \quad i=1,2, \ldots, M \\
& \sum_{i=1}^{M} v_{i}\left(\beta_{j} x_{i j}\right)-\sum_{r=1}^{S} u_{r}\left[\bar{y}_{r j}+b_{r j} \sigma F^{-1}\left(1-\alpha_{j}\right)\right] \geq 0, \\
& u_{r} \geq 0, r=1, \ldots, S \quad r=1,2, \ldots, S \\
& v_{i} \geq 0, i=1, \ldots, M \quad i=1,2, \ldots M \text {. }
\end{aligned}
$$

In the model shown above, $\bar{y}_{r j}$ expresses the expected value of the $r$ th output of the $j$ th DMUs. While $\beta_{j}$ expresses the expected level activity of DMU, and $\alpha_{j}$ indicates the probability that the activity level is more than $\beta_{j}$. 
TABLE 1. Input and output data set.

\begin{tabular}{|c|c|c|c|c|c|c|c|c|}
\hline \multirow{2}{*}{$\begin{array}{l}\text { DMU } \\
\begin{array}{l}\text { Number of } \\
\text { branch }\end{array}\end{array}$} & \multicolumn{3}{|c|}{ Input data set } & \multicolumn{4}{|c|}{ Output data set } & \multirow{2}{*}{$\begin{array}{l}\begin{array}{l}\text { Flexible } \\
\text { data set }\end{array} \\
\begin{array}{l}\text { Number of } \\
\text { staff }\end{array}\end{array}$} \\
\hline & $\begin{array}{l}\text { Branch } \\
\mathrm{m}^{2}\end{array}$ & $\begin{array}{l}\text { Rent } \\
\text { Expense }\end{array}$ & $\begin{array}{l}\text { Personal } \\
\text { Expense }\end{array}$ & $\begin{array}{l}\text { Banking } \\
\text { Service } \\
\text { Revenue }\end{array}$ & $\begin{array}{l}\text { Cash } \\
\text { Credits }\end{array}$ & $\begin{array}{l}\text { Credit } \\
\text { Card } \\
\text { Turnover }\end{array}$ & $\begin{array}{l}\text { Bussiness } \\
\text { Card } \\
\text { Turnover }\end{array}$ & \\
\hline 1 & 784 & 200 & 879 & 1607.36 & 5430.34 & 932.27 & 2152.46 & 17 \\
\hline 2 & 461 & 161 & 1025 & 1477.45 & 10427.11 & 1116.47 & 1560.40 & 20 \\
\hline 3 & 460 & 83 & 703 & 968.73 & 2532.17 & 618.62 & 1988.32 & 12 \\
\hline 4 & 364 & 132 & 580 & 761.14 & 1385.73 & 401.95 & 564.76 & 12 \\
\hline 5 & 387 & 162 & 455 & 539.33 & 2026.53 & 477.23 & 1011.18 & 9 \\
\hline 6 & 1040 & 145 & 535 & 581.56 & 2691.40 & 237.22 & 401.15 & 9 \\
\hline 7 & 360 & 408 & 471 & 840.50 & 5171.15 & 362.49 & 529.73 & 10 \\
\hline 8 & 395 & 178 & 497 & 430.97 & 1333.33 & 495.06 & 1823.89 & 9 \\
\hline 9 & 460 & 238 & 615 & 1383.38 & 3044.55 & 216.70 & 1946.92 & 11 \\
\hline 10 & 290 & 146 & 437 & 308.26 & 1019.92 & 191.65 & 823.95 & 8 \\
\hline 11 & 398 & 349 & 1056 & 4146.62 & 10785.92 & 604.53 & 3032.52 & 20 \\
\hline 12 & 620 & 192 & 679 & 1286.14 & 6956.32 & 424.16 & 641.51 & 13 \\
\hline 13 & 515 & 201 & 536 & 547.06 & 1562.99 & 122.84 & 110.05 & 10 \\
\hline 14 & 322 & 222 & 495 & 504.48 & 1898.43 & 96.1 & 537.87 & 9 \\
\hline 15 & 361 & 85 & 425 & 276.44 & 723.61 & 377.75 & 705.59 & 8 \\
\hline 16 & 410 & 144 & 803 & 1336.58 & 3387.51 & 728.87 & 321.26 & 15 \\
\hline 17 & 447 & 220 & 775 & 1527.39 & 4345.87 & 403.67 & 140.38 & 15 \\
\hline 18 & 685 & 481 & 472 & 375.32 & 1731.77 & 81.84 & 55.71 & 7 \\
\hline 19 & 390 & 153 & 772 & 1527.9 & 4648.57 & 364.15 & 1924.72 & 14 \\
\hline 20 & 620 & 189 & 590 & 422.56 & 1569.49 & 355.29 & 697.87 & 9 \\
\hline 21 & 450 & 135 & 549 & 1990.22 & 4776.31 & 7.12 & 101.67 & 7 \\
\hline 22 & 414 & 113 & 638 & 1756.28 & 3020.29 & 1409.49 & 1605.89 & 14 \\
\hline 23 & 237 & 224 & 893 & 2146.88 & 6503.52 & 444.48 & 291.63 & 17 \\
\hline 24 & 376 & 327 & 494 & 521.98 & 1733.29 & 84.29 & 185.29 & 9 \\
\hline 25 & 384 & 150 & 541 & 858.66 & 2210.2 & 333.59 & 1251.78 & 10 \\
\hline 26 & 520 & 248 & 532 & 648.15 & 2369.67 & 157.04 & 446.98 & 9 \\
\hline 27 & 221 & 74 & 355 & 647.56 & 270.27 & 260.34 & 996.46 & 8 \\
\hline 28 & 344 & 133 & 525 & 601.82 & 1581.07 & 559.95 & 724.80 & 9 \\
\hline 29 & 392 & 102 & 389 & 231.96 & 880.22 & 126.68 & 930.90 & 7 \\
\hline 30 & 945 & 246 & 1120 & 1872.74 & 8134.44 & 754.39 & 743.61 & 19 \\
\hline
\end{tabular}

\subsection{Data description and results of existing models}

The Banks' ranked is as the first among to the participating banks in funds collected and extended and asset size. It also maintains its first place among participating banks, which invest in gold banking, and third place in the entire banking sector. On the other hand, with its 414 branches, it is the 11th largest bank in the country by the number of branches. It increased its net profit by $30 \%$ compared to the previous year by more than 850 million $€$. The total assets of the bank is around 75 billion $€$. Its own assets reached over 5 billion $€$.

Efficiency of 30 different branches of the bank that operate in Turkey were analyzed by Weighted Stochastic Imprecise Data Envelopment Analysis (WSIDEA). The model used four inputs, three outputs and one flexible data. The data used in the analysis are as follows:

- Input data set:

- Field Measurements of Branches.

- Rent Expenses. 
TABLE 2. The standard deviation of the output set.

\begin{tabular}{|c|c|c|c|c|}
\hline \multirow{2}{*}{$\begin{array}{l}\text { DMU } \\
\text { Number of } \\
\text { branches }\end{array}$} & \multicolumn{4}{|c|}{ The standard deviation of the output set } \\
\hline & $\begin{array}{l}\text { B. Service } \\
\text { Revenue_std }\end{array}$ & $\begin{array}{l}\text { Cash } \\
\text { Credits_std }\end{array}$ & $\begin{array}{l}\text { C. Cart } \\
\text { Turnover_Std }\end{array}$ & $\begin{array}{l}\text { B. Cart } \\
\text { Turnover_St }\end{array}$ \\
\hline 1 & 105.4 & 356.09 & 61.133 & 141.14 \\
\hline 2 & 96.88 & 683.75 & 73.211 & 102.32 \\
\hline 3 & 63.52 & 166.04 & 40.565 & 130.38 \\
\hline 4 & 49.91 & 90.87 & 26.357 & 37.03 \\
\hline 5 & 35.37 & 132.89 & 31.294 & 66.31 \\
\hline 6 & 38.13 & 176.49 & 15.556 & 26.31 \\
\hline 7 & 55.11 & 339.09 & 23.77 & 34.74 \\
\hline 8 & 28.26 & 87.43 & 32.463 & 119.6 \\
\hline 9 & 90.71 & 199.64 & 14.21 & 127.67 \\
\hline 10 & 20.21 & 66.88 & 12.567 & 54.03 \\
\hline 11 & 271.91 & 707.27 & 39.641 & 198.85 \\
\hline 12 & 84.34 & 456.15 & 27.814 & 42.07 \\
\hline 13 & 35.87 & 102.49 & 8.055 & 7.22 \\
\hline 14 & 33.08 & 124.49 & 6.301 & 35.27 \\
\hline 15 & 18.13 & 47.45 & 24.771 & 46.27 \\
\hline 16 & 87.64 & 222.13 & 47.795 & 21.07 \\
\hline 17 & 100.16 & 284.98 & 26.47 & 9.21 \\
\hline 18 & 24.61 & 113.56 & 5.367 & 3.65 \\
\hline 19 & 100.19 & 304.82 & 23.878 & 126.21 \\
\hline 20 & 27.71 & 102.92 & 23.298 & 45.76 \\
\hline 21 & 130.51 & 313.2 & 0.467 & 6.67 \\
\hline 22 & 115.17 & 198.05 & 92.425 & 105.3 \\
\hline 23 & 140.78 & 426.46 & 29.146 & 19.12 \\
\hline 24 & 34.23 & 113.66 & 5.527 & 12.15 \\
\hline 25 & 56.31 & 144.93 & 21.875 & 82.08 \\
\hline 26 & 42.5 & 155.39 & 10.298 & 29.31 \\
\hline 27 & 42.46 & 17.72 & 17.072 & 65.34 \\
\hline 28 & 39.46 & 103.68 & 36.718 & 47.53 \\
\hline 29 & 15.21 & 57.72 & 8.307 & 61.04 \\
\hline 30 & 122.8 & 533.41 & 49.468 & 48.76 \\
\hline
\end{tabular}

- Personnel Expenses.

- Output data set:

- Business Credit Card Number.

- Banking Service Revenue.

- Number of Credit Cards.

- Number of Cash Loans.

- Flexible data Set:

- Number of Staff.

The output data used in the analysis was calculated as same as calculation of Program Evaluation and Review Technics and Ctitical Path Method (PERT/CPM). As Sueyoshi [44] used in his proposed model the most likely expectation, the optimistic expectation and the pessimistic expectation (Tabs. 1 and 2).

The efficiency results obtained by applying the CCR-I, BCC-I, Absulate Wighted Restriction, Imprecise DEA, stochastic DEA and Slack Base DEA models are shown in Table 3.

As can be seen in Table 3, efficiency scores may vary according to the model used for each decision-making unit. For example; first decision-making unit was fully effective in the imprecise DEA (IDEA) model, but not 
TABLE 3. DEA models' efficiency scores.

\begin{tabular}{lllllll}
\hline \hline DMU & Absulate W.R. & BCC-I & CCR-I & IDEA & SBM-GRT & SDEA \\
\hline 1 & 0.899 & 0.905 & 0.903 & 1.000 & 0.808 & 0.887 \\
2 & 1.000 & 1.000 & 1.000 & 1.000 & 1.000 & 0.984 \\
3 & 1.000 & 1.000 & 1.000 & 1.000 & 1.000 & 0.981 \\
4 & 0.419 & 0.750 & 0.420 & 0.859 & 0.428 & 0.412 \\
5 & 0.714 & 1.000 & 0.767 & 1.000 & 0.650 & 0.752 \\
6 & 0.498 & 0.881 & 0.558 & 0.963 & 0.427 & 0.548 \\
7 & 0.924 & 1.000 & 1.000 & 1.000 & 1.000 & 0.978 \\
8 & 1.000 & 1.000 & 1.000 & 1.000 & 1.000 & 0.980 \\
9 & 0.973 & 1.000 & 0.997 & 1.000 & 0.896 & 0.979 \\
10 & 0.557 & 0.964 & 0.558 & 0.864 & 0.546 & 0.548 \\
11 & 1.000 & 1.000 & 1.000 & 1.000 & 1.000 & 0.986 \\
12 & 0.994 & 1.000 & 1.000 & 1.000 & 1.000 & 0.981 \\
13 & 0.290 & 0.755 & 0.305 & 0.632 & 0.326 & 0.299 \\
14 & 0.361 & 0.896 & 0.393 & 0.924 & 0.435 & 0.387 \\
15 & 0.569 & 1.000 & 0.599 & 1.000 & 0.543 & 0.588 \\
16 & 0.660 & 0.811 & 0.683 & 0.971 & 0.637 & 0.668 \\
17 & 0.588 & 0.757 & 0.594 & 1.000 & 0.551 & 0.583 \\
18 & 0.305 & 1.000 & 0.411 & 1.000 & 0.321 & 0.402 \\
19 & 0.924 & 0.981 & 0.942 & 1.000 & 0.906 & 0.923 \\
20 & 0.461 & 0.898 & 0.557 & 0.786 & 0.398 & 0.547 \\
21 & 1.000 & 1.000 & 1.000 & 1.000 & 1.000 & 0.980 \\
22 & 1.000 & 1.000 & 1.000 & 1.000 & 1.000 & 0.985 \\
23 & 0.863 & 1.000 & 1.000 & 1.000 & 1.000 & 0.980 \\
24 & 0.309 & 0.844 & 0.347 & 0.497 & 0.354 & 0.339 \\
25 & 0.736 & 0.912 & 0.741 & 0.865 & 0.689 & 0.728 \\
26 & 0.421 & 0.833 & 0.478 & 0.728 & 0.407 & 0.471 \\
27 & 0.872 & 1.000 & 0.946 & 1.000 & 0.866 & 0.931 \\
28 & 0.587 & 1.000 & 0.679 & 0.909 & 0.537 & 0.666 \\
29 & 0.681 & 1.000 & 0.719 & 1.000 & 0.645 & 0.707 \\
30 & 0.799 & 0.816 & 0.814 & 1.000 & 0.655 & 0.799 \\
\hline & & & & & & \\
\hline
\end{tabular}

in other models. Or, the 18th decision-making unit is effective in the BCC-I model, but in the CCR-I model or SBM-GRT model.

\section{Weighted stochastic imprecise Data Envelopment Analysis}

All of the above-described models have advantages and disadvantages. Rather, the advantage of one is also the missing part of another. For example, while the model proposed by Sueyoshi [44] allows the use of stochastic data, the model proposed by Cook and Zhu [15] is designed for purely deterministic data. Likewise, while we are allowed to categorise input and output data with imprecise DEA, we are not allowed to do in the model proposed by Sueyoshi $[15,44]$.

For this reason, in our study, a different model is proposed apart from the current DEA-based approaches in the literature. The model we proposed is a new approach of the model which was proposed by Cosgun and Yurdakul [18]. The main difference of the model we proposed from others is that the decision variables are weighted and the data set are queued as importance of data sets according to the experts. The proposed model is advantageous in several aspects from the models available in the literature. This model, unlike the model proposed by Cosgun and Yurdakul [18], is an approach that saves the weight of the input and output sets that 
constitute the activity score from zero and integrates the expert opinion into the model. So, with this proposed approach;

- Using stochastic data, future efficiency levels of DMUs will be measured.

- It can be possible to determine which group of data sets can be considered either as input or output.

- According to the experts, it is possible to analyze which data groups that make up input and output sets are more important than others.

In traditional DEA models, expert opinions - due to the nature of the model - are not taken into account. For example, while the relatively less important data set is given high weight by the model, the contribution to the model can be eliminated by giving zero value to a more important data. In this respect, zero weight will be prevented for all data sets, and we will determine the importance of data sets by referring to expert opinions in the model.

With the above-mentioned features, by this approach, users will have a chance to analyze DMU's more accurately and obtain more realistic activity scores. The mathematical representation of the weighted stochastic imprecise DEA (WSIDEA) model is as follows:

$$
\begin{aligned}
& \operatorname{Max}=\sum_{r=1}^{S} u_{r} \bar{y}_{r 0}+\sum_{l=1}^{L} \delta_{l} \varpi_{l 0} \\
& \text { s.t. } \\
& \sum_{i=1}^{M} v_{i} x_{i 0}+\sum_{l=1}^{L} \gamma_{l} \varpi_{l 0}-\sum_{l=1}^{L} \delta_{l} \varpi_{l 0}=1 \\
& \beta_{j} \sum_{i=1}^{M} v_{i} x_{i j}-\sum_{r=1}^{S} u_{r} \bar{y}_{r j}-\sum_{l=1}^{L} \delta_{l} \varpi_{l j}-\phi^{-1}\left(1-\alpha_{j}\right)\left\{\sum_{r=1}^{S} u_{r} \lambda_{r j}+\sum_{l=1}^{L} \delta_{l} \pi_{l j}\right\} \geq 0 \\
& 0 \leq \delta_{l} \leq M d_{l} \quad l=1,2, \ldots, L \\
& \delta_{l} \leq \gamma_{l} \leq \delta_{l} M\left(1-d_{l}\right) \quad l=1,2, \ldots, L \\
& v_{i} \geq P_{1} \quad i=1,2, \ldots, M \\
& u_{r} \geq P_{2} \quad r=1,2, \ldots, S \\
& v_{i} \geq k * v_{(i+1)} \quad i=1,2, \ldots, M \\
& u_{r} \geq k * u_{(r+1)} \quad r=1,2, \ldots, S \\
& d_{l} \in\{0,1\} \quad \forall l \\
& u_{r}, v_{i}, \delta_{l}, \gamma_{l} \geq 0 \quad \forall r, i, l .
\end{aligned}
$$

In the model shown above, $u_{r}, v_{i}, \gamma_{l}$ represent the weights of output, input and flexible variables, respectively. The parameters $\bar{y}_{r}, \varpi_{l}$ show the expected value of the $r$ th output and $l$ th flexible data sets, respectively. $\lambda_{r j}$ and $\pi_{l j}$ represent the standard deviation of the output and inputs, respectively. The objective function (4.1) of the WSIDEA model aims to maximize the outputs of DMUs. It includes data set which is not known whether it is an output or input in advance. Thus, it allows to consider imprecise data set. In the equation (4.3) $\beta_{j}$ is an aspiration level and, $\phi^{-1}$ shows the inverse of the cumulative normal distribution. Finally, $\alpha_{j}$ represents the decision-maker's risk criterion. Therefore, $1-\alpha_{j}$ also indicates the rate of reaching the requirements.

Equations (4.4) and (4.5) assure that $d_{l}=1$ when relevant data needs to be considered as output and $d_{l}=0$ otherwise. $d_{l}$ is a binary variable that takes a value from $\{0,1\}$. In equations (4.6) and (4.7), $P_{1}$ and $P_{2}$ are parameters that represent the minimum value that the relevant inputs and outputs can take. Equations (4.8) and (4.9) are the constraints where the expert opinions are included in the model. "k" is the constant parameter.

Sueyoshi [44] used PERT/CPM methods, which are frequently used in pject planning, time and activity scheduling fields, to obtain stochastic outputs In WSIDEA model, a similar method is used to obtain stochastic outputs. The PERT/CPM methods allow many dependent and independent activities in a project to be 
sequenced in terms of time. The PERT/CPM methods enable the determination of prior activities, deduction of the completion time for each activity, and finally determination of the critical path of the project. It also ensures the efficiency of the project. In some cases, where the exact time of activities are not known, the probability of completing the project in the specified time can be determined by PERT. In order to use the PERT method, three different completion times for each activity are required: Optimistic duration (OD), average/expected duraon (ED), and pessimistic duration (PD). These time durations are assumed to fit the beta distribution. In this respect, the mean and variance of $T$ (duration of the activity) are calculated as follows:

$$
\begin{aligned}
E(T) & =(\mathrm{OD}+4 * \mathrm{ED}+\mathrm{PD}) / 6 \\
\operatorname{Var}(T) & =(\mathrm{ED}-\mathrm{OD}) / 6 .
\end{aligned}
$$

In the WSIDEA model, three different data sets are used, namely, inputs, outputs, and the data set whose class is imprecise. Inputs are deterministic, outputs are stochastic. $\bar{y}_{r j}$ are expected values of outputs and are calculated using equations given in (4.12) and (4.13). $\varpi_{l j}$ refers to the outputs in the imprecise data set. The data used in the model are aligned according to the opinions of the experts, from the least to the most important one.

It is thought that the WSIDEA method proposed in the study has contribution to the DEA literature in two ways. The first contribution is the response ability to three shortcomings of the DEA methods with a single hybrid model. First of all, In the WSIDEA method, stochastic data can be used. Secondly, the imprecise class of data whether it is input or output can be determined and lastly the data is weighted to prevent it to take a zero value. In this respect, due to those skills of the model, it is thought that the most accurate efficiency results are achieved by eliminating these problems.

On the other hand, as it is known, DEA methods measure the relative efficiency levels of similar DMUs. The results obtained with DEA methods contain valuable information for researchers who will analyze the efficiency of the related DMUs. Data sets are not different from each other in DEA-based models. However, this situation may differ for users. Some data sets may be relatively more important than other data sets. In this respect, the WSIDEA method incorporates expert opinion into the model and enables to determine which data set is more effective. Thus, more accurate results are obtained.

Prior to the solution of the model, experts from four different banking sectors were interviewed and asked to sort the data according to the importance. Each of the people whose knowledge is consulted are experts in the professions of different banks and different departments in the banking sector. Information related to the experts are as follows;

- The first expert works as a private customer representative of a bank and has at least 5 years of experience in the profession.

- The second expert works as a sales and customer representative in a different bank, and he also has more than 5 years of experience.

- The third expert has 7 years of experience in the bank sector as the second specialist and works as an assistant specialist.

- The fourth expert has 6 years of experience as an investment consultant in a different bank than the other experts.

\subsection{Results of WSIDEA and comparisons}

According to the opinions of the relevant experts, the ranking of the data from the order of importance to the least is as follows;

- Output data set;

- Banking Service Revenue.

- Cash Credit.

- Credit Card Turnover. 
TABLE 4. The efficiency scores of WSIDEA.

\begin{tabular}{llllll}
\hline \hline DMU & Efciency score & DMU & Efciency score & DMU & Efciency score \\
\hline 1 & 0.745 & 11 & 0.899 & 21 & 0.625 \\
2 & 0.794 & 12 & 0.795 & 22 & 0.895 \\
3 & 0.714 & 13 & 0.607 & 23 & 0.771 \\
4 & 0.716 & 14 & 0.900 & 24 & 0.616 \\
5 & 0.792 & 15 & 0.694 & 25 & 0.747 \\
6 & 0.619 & 16 & 0.627 & 26 & 0.618 \\
7 & 0.882 & 17 & 0.670 & 27 & 0.900 \\
8 & 0.900 & 18 & 0.517 & 28 & 0.643 \\
9 & 0.839 & 19 & 0.735 & 29 & 0.739 \\
10 & 0.696 & 20 & 0.552 & 30 & 0.574 \\
\hline
\end{tabular}

TABLE 5. Results of existing six DEA and WSIDEA models.

\begin{tabular}{|c|c|c|c|c|c|c|c|}
\hline $\mathrm{DMU}$ & Absulate W.R. & BCC-I & CCR-I & IDEA & SBM-GRT & SDEA & WSIDEA \\
\hline 1 & 0.899 & 0.905 & 0.903 & 1.000 & 0.808 & 0.887 & 0.745 \\
\hline 2 & 1.000 & 1.000 & 1.000 & 1.000 & 1.000 & 0.984 & 0.794 \\
\hline 3 & 1.000 & 1.000 & 1.000 & 1.000 & 1.000 & 0.981 & 0.714 \\
\hline 4 & 0.419 & 0.750 & 0.420 & 0.859 & 0.428 & 0.412 & 0.716 \\
\hline 5 & 0.714 & 1.000 & 0.767 & 1.000 & 0.650 & 0.752 & 0.792 \\
\hline 6 & 0.498 & 0.881 & 0.558 & 0.963 & 0.427 & 0.548 & 0.619 \\
\hline 7 & 0.924 & 1.000 & 1.000 & 1.000 & 1.000 & 0.978 & 0.882 \\
\hline 8 & 1.000 & 1.000 & 1.000 & 1.000 & 1.000 & 0.980 & 0.900 \\
\hline 9 & 0.973 & 1.000 & 0.997 & 1.000 & 0.896 & 0.979 & 0.839 \\
\hline 10 & 0.557 & 0.964 & 0.558 & 0.864 & 0.546 & 0.548 & 0.696 \\
\hline 11 & 1.000 & 1.000 & 1.000 & 1.000 & 1.000 & 0.986 & 0.899 \\
\hline 12 & 0.994 & 1.000 & 1.000 & 1.000 & 1.000 & 0.981 & 0.795 \\
\hline 13 & 0.290 & 0.755 & 0.305 & 0.632 & 0.326 & 0.299 & 0.607 \\
\hline 14 & 0.361 & 0.896 & 0.393 & 0.924 & 0.435 & 0.387 & 0.900 \\
\hline 15 & 0.569 & 1.000 & 0.599 & 1.000 & 0.543 & 0.588 & 0.694 \\
\hline 16 & 0.660 & 0.811 & 0.683 & 0.971 & 0.637 & 0.668 & 0.627 \\
\hline 17 & 0.588 & 0.757 & 0.594 & 1.000 & 0.551 & 0.583 & 0.670 \\
\hline 18 & 0.305 & 1.000 & 0.411 & 1.000 & 0.321 & 0.402 & 0.517 \\
\hline 19 & 0.924 & 0.981 & 0.942 & 1.000 & 0.906 & 0.923 & 0.735 \\
\hline 20 & 0.461 & 0.898 & 0.557 & 0.786 & 0.398 & 0.547 & 0.552 \\
\hline 21 & 1.000 & 1.000 & 1.000 & 1.000 & 1.000 & 0.980 & 0.625 \\
\hline 22 & 1.000 & 1.000 & 1.000 & 1.000 & 1.000 & 0.985 & 0.895 \\
\hline 23 & 0.863 & 1.000 & 1.000 & 1.000 & 1.000 & 0.980 & 0.771 \\
\hline 24 & 0.309 & 0.844 & 0.347 & 0.497 & 0.354 & 0.339 & 0.616 \\
\hline 25 & 0.736 & 0.912 & 0.741 & 0.865 & 0.689 & 0.728 & 0.747 \\
\hline 26 & 0.421 & 0.833 & 0.478 & 0.728 & 0.407 & 0.471 & 0.618 \\
\hline 27 & 0.872 & 1.000 & 0.946 & 1.000 & 0.866 & 0.931 & 0.900 \\
\hline 28 & 0.587 & 1.000 & 0.679 & 0.909 & 0.537 & 0.666 & 0.643 \\
\hline 29 & 0.681 & 1.000 & 0.719 & 1.000 & 0.645 & 0.707 & 0.739 \\
\hline 30 & 0.799 & 0.816 & 0.814 & 1.000 & 0.655 & 0.799 & 0.574 \\
\hline
\end{tabular}




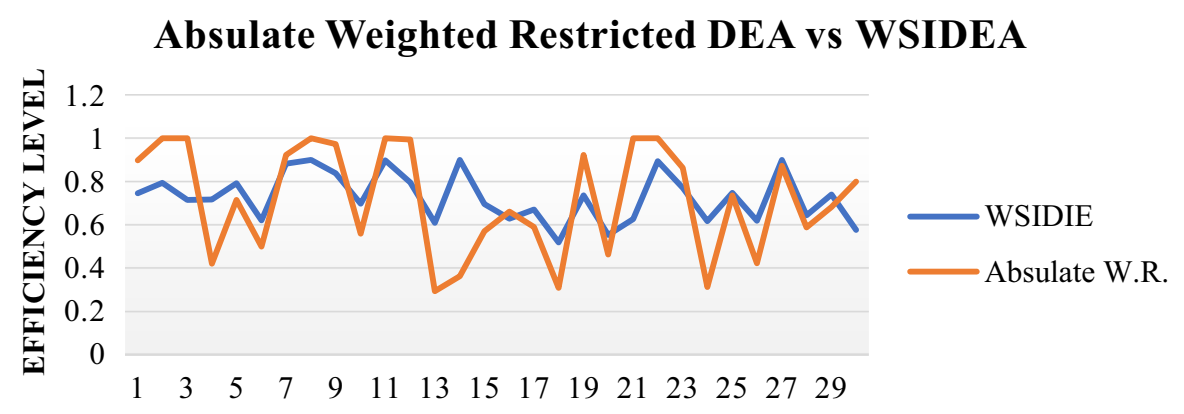

FiguRE 1. Comparison of absulate Weighted Restricted DEA and WSIDEA.

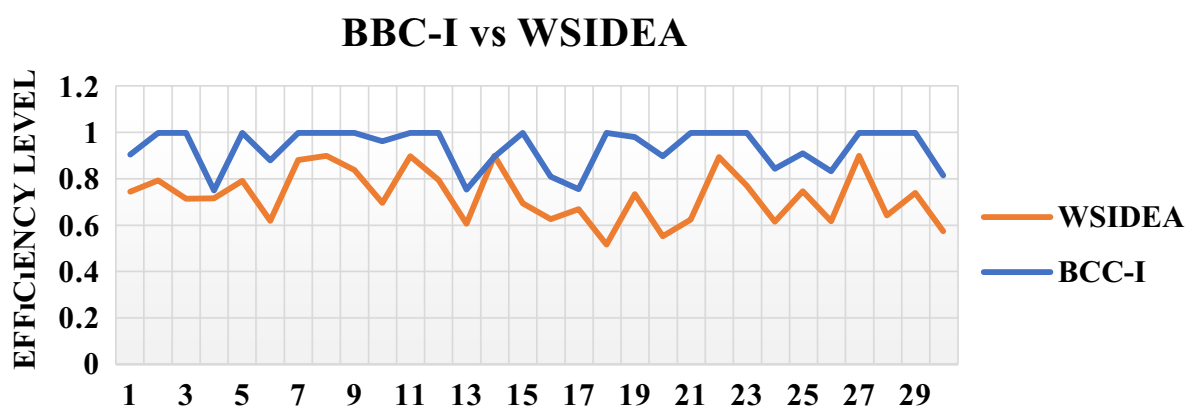

Figure 2. Comparison of BCC-I and WSIDEA.

- Bussiness Card Turnover.

- Input data set;

- Field Size of Branches.

- Rent Expenses.

- Personnel Expenses.

Table 4 presents the efficiency scores of each DMU in the WSIDEA model. According to the results of the analysis, no branch is fully (100\%) effective. However, the 7th and 27th branches reached to the highest level of activity with $90 \%$, while the 18th and 20th branches had the lowest level of efficiency.

The reason for this is that the WSIDEA model is an integrated model, and it does not allow any data to be excluded from the analysis by taking a value of zero, which makes model more realistic. This means that the results in other models show a partially unrealistic level of efficiency. In fact, a misleading analysis was conducted showing that many DMU that are not fully effective are effective. For example, branches 21, 22, 23 are fully $(100 \%)$ effective in more than one model. However, in none of the WSIDEA models they were fully effective. This means that non-WSIDEA models show these branches at an activity level where they are actually not that effective.

Table 5 combines the results of the six DEA models analyzed in the previous section and WSIDEA models into single table. As seen in Table 5, DMUs that reach high efficiency levels in other models are at lower efficiency levels compared to the WSIDEA model. On the other hand, some DMUs such as the 4th DMU achieved higher efficiency levels unlike other five models.

Figures 1-6 show the comparisons of other DEA models and the WSIDEA model so that the statements explained above can be better observed. 


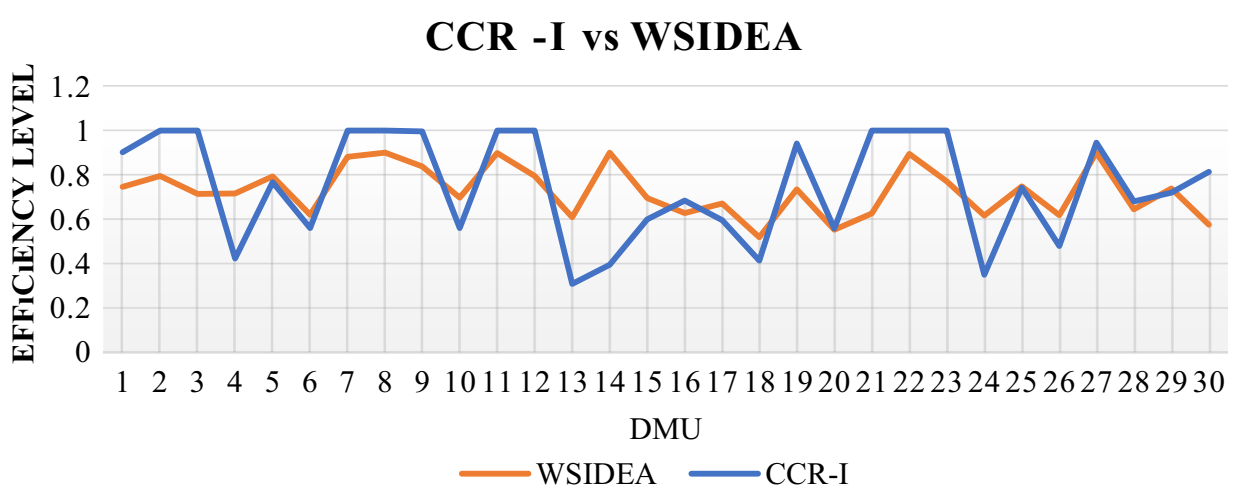

Figure 3. Comparison of CCR-I and WSIDEA.

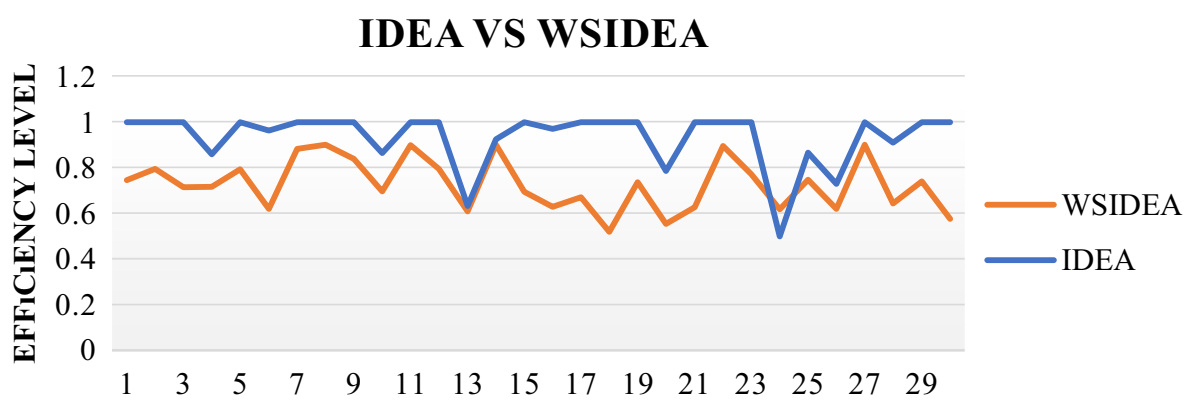

Figure 4. Comparison of IDEA and WSIDEA.

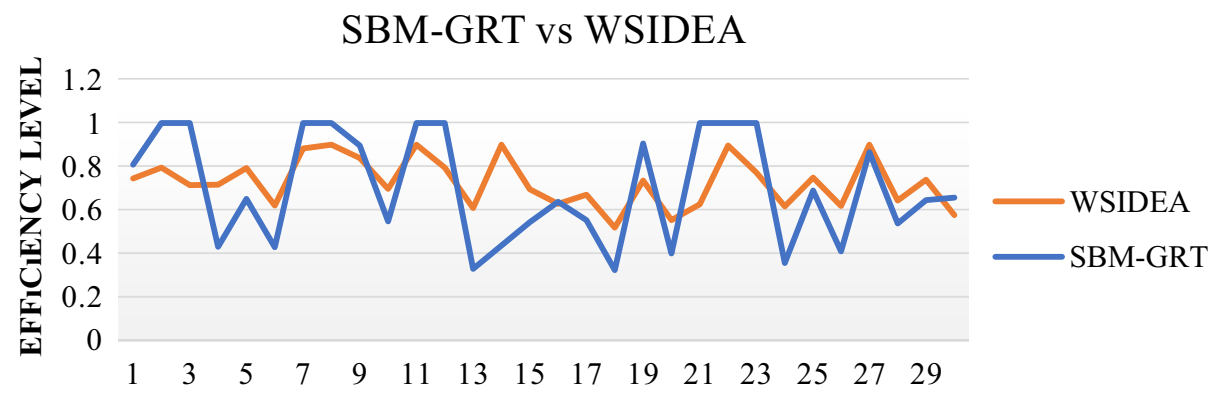

Figure 5. Comparison of SBM-GRT and WSIDEA.

As shown in the Figures 1-6, DEA-based models other than WSIDEA have an unrealistic level of efficiency for many DMUs. However, it can easily be observed that the unrealistic high efficiency levels decrease when the expert opinion is included to the model and the input and output weights in the model are prevented to take the value of zero. Therefore, we believe that the WSIDEA model proposed in this study gives more consistent results. 


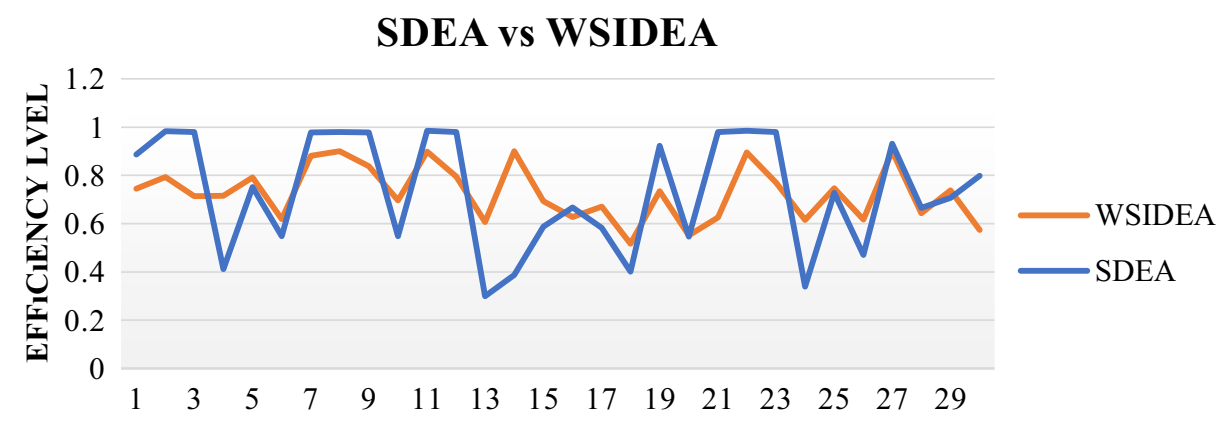

Figure 6. Comparison of SDEA and WSIDEA.

\subsection{Discussion of the results}

The WSIDEA method proposed in this study contributes to the DEA literature in two ways. The first contribution is the response ability to three shortcomings of the DEA methods with a single hybrid model. On the other hand, the WSIDEA method incorporates expert opinion into the model and enables to determine which data set is more important. Thus, more accurate results are obtained.

The results of the WSIDEA model differ in many respects compared to the other six DEA models used in the study. First of all, most of the DMUs that are determined as completely efficient in other models indeed are not efficient, which is caught by WSIDEA method. Table 6 indicates the number of DMUs reaching $90 \%$ and above efficiency level on model basis.

This situation actually indicates the presence of an unreal or inflated efficiency level. In fact, it misleads researchers by showing some DMUs as fully efficient, which indeed have lower efficiency levels. Thus, the comments constructed based on these results will also be erroneous. However, WSIDEA model correct this situation. For instance, while the 2nd, 3rd and 21st DMUs are shown as fully efficient in other models, they are at a lower efficiency level in the WSIDEA model. Thus, thanks to WSIDEA, researchers will be able to make more accurate analysis and interpretations.

The biggest difference between the results of the WSIDEA model and the results of the other models was experienced with the BCC-I model. In the BCC-I model, 20 of 30 DMUs have reached an efficiency level of $90 \%$ and above. This value has emerged as three for WSIDEA. Considering Figure 2, it will be seen that the results of the two models are comparable parallel, but the BCC-I model is at a much higher efficiency level compared to the WSIDEA model. In Absolute W.R model, the number of DMUs reaching $90 \%$ and above efficiency level is 10 . This value is the next lowest value in the WSIDEA model. Considering this result, it can be said that it is important to weight the variables in the model.

Finally, the main purpose of the WSIDEA model is to determine the most realistic efficiency level for each DMU. In order to do this, it includes many different features such as using both deterministic and stochastic data, providing the data to be sorted in order of importance by referring to the knowledge of experts, or determining the class of uncertain data which group it belongs to. However, apart from these, the WSIDEA model does not aim to increase the efficiency levels of DMUs. For this reason, it does not provide an argument to improve these results after efficiency analysis.

TABLE 6. Number of DMUs which reached $90 \%$ and above efficiency level.

\begin{tabular}{lllllll}
\hline \hline Absolute W.R. & BCC-I & CCR-I & IDEA & SBM-GRT & SDEA & WSIDEA \\
\hline 10 & 20 & 13 & 23 & 10 & 12 & 3 \\
\hline
\end{tabular}


TABLE 7. Sensitivity analysis of the WSIDEA.

\begin{tabular}{|c|c|c|c|c|c|}
\hline \multicolumn{5}{|c|}{ Outputs } & \multirow{2}{*}{$\begin{array}{l}\text { Input } \\
\text { Rent } \\
\text { Expenses } \\
\text { is issued }\end{array}$} \\
\hline DMU & $\begin{array}{l}\text { Bussiness } \\
\text { Card } \\
\text { Turnover } \\
\text { is issued }\end{array}$ & $\begin{array}{l}\text { Banking Ser- } \\
\text { vice revenue is } \\
\text { issued }\end{array}$ & $\begin{array}{l}\text { Cash credit is } \\
\text { issued }\end{array}$ & $\begin{array}{lr}\text { Credi } & \text { Card } \\
\text { Turnover } & \text { is } \\
\text { issued } & \end{array}$ & \\
\hline 3 & - & $-14 \%$ & - & - & $14 \%$ \\
\hline 7 & - & - & $14 \%$ & $-13 \%$ & - \\
\hline 8 & $26 \%$ & $-26 \%$ & - & - & - \\
\hline 9 & $13 \%$ & $-14 \%$ & - & - & - \\
\hline 12 & - & - & $14 \%$ & $-12 \%$ & - \\
\hline 16 & $-13 \%$ & - & - & - & - \\
\hline 21 & $-19 \%$ & $23 \%$ & - & - & - \\
\hline 22 & - & - & - & - & - \\
\hline 23 & $-13 \%$ & - & - & - & $7 \%$ \\
\hline 29 & $13 \%$ & $-15 \%$ & - & - & - \\
\hline 30 & $-12 \%$ & - & $9 \%$ & - & $7 \%$ \\
\hline
\end{tabular}

\subsection{Sensitivity analysis}

After the analyses which are presented above, a sensitivity analysis was performed to examine the sensitivity of the model to the data sets. In the sensitivity analysis, it was desired to observe how much each data set affects the efficiency of the related bank branch. For this reason, as applied in Şahin et al. [41], the responses of branches to data sets were analyzed by removing each data set from the analysis one by one, seperately. During the anaylsis process, the effect of each output set in the output data group was examined first. Then the input group was analyzed. Considering the results of the analysis (Tab. 7), the data set that the DMUs are very sensitive to is the "Banking service income". When this data set was removed from the model, more than $10 \%$ change was observed in the efficacy scores of many DMUs [41]. For example, a $23 \%$ deterioration was observed in the 21st DMU. In addition, when the "Bussiness card turnover" is analyzed, there was a $20 \%$ decrease in the effectiveness level of the 8th, 9th and 29th DMUs, while an improvement was observed in the 21st and 23rd for more than 15\%. On the other hand, 7th and 12th DMUs, were not sensitive to "Bussines card" or "Banking service income", but they were sensitive to other two data sets; "Cash credit" and "Credit card turnover". Secondly, input data sets have much less impact comparing to the output data sets. In these data sets, it was observed that the highest sensitivity branches were against the "Rental expenses". In other words, when the data set of "Rental expenses" was removed, a $10 \%$ improvement was observed in the 3rd and 23rd DMUs, whereas the efficiency levels of the 3rd, 8th, 9th and 29th DMUs improved by $15 \%$. In addition, when "Bussiness card turnover" is analysed, there was a $20 \%$ decrease in the effectiveness level of the 8th, 9th and 29th DMUs, whereas in the 21st and 23rd a 15\% improvement was observed in the DMUs. Another result is that the bank branches that are most sensitive to data sets are the 3rd, 8th, 21st and 30th DMUs.

\section{Conclusions}

In this study, the efficiency levels of the branches of a bank were analyzed with DEA based models, which are frequently used in the literature, and with a newly proposed model. There are several DEA based models and approaches in the literature. Although these approaches operate essentially on the same principles, there are differences between them in terms of the way they operate and the way they use the data. Therefore, a DMU that is determined as effective according to one model may not be effective in another model. 
Furthermore, in this study, a weighted stochastic imprecise DEA (WSIDEA) model was introduced and the efficiency level of the bank branches was examined. The efficiency score of each DMU was also analyzed with the CCR-I model and differences were examined. The efficiency of each branch resulted in dissimilar levels in each DEA models. If any DMU has a "1" activity score in the DEA, it means that DMU is fully effective. If more than one DMU has a "1" score, then each is considered to be fully effective. While many DMUs were determined as fully effective in more than one model, no branch was fully effective indeed, which is caught by the WSIDEA model.

As a result of the study, it was observed that the model we proposed was an integrated model that eliminated the deficiencies of other DEA based models and gave more realistic efficiency results. Apart from the proposed model, it was observed that the DMUs that were efficient in other models were not determined as efficient in the WSIDEA model. With the participation of the expert opinions into the model, the data sets were ranked according to their importance and contributed to obtain more accurate results.

In this study, the developed model was analyzed through the branches of a bank operating in Turkey. In addition, applying the model in other sectors where the probability and the efficiency analysis for the future are much more important due to the stochastic environment will be beneficial in terms of the adequacy and validity of the proposed research. Moreover, once the model applied to other sectors, the proposed model's results can be compared with other non-DEA based efficiency analysis methods' results.

\section{REFERENCES}

[1] R.G. Amin and M. Toloo, Finding the most efficient DMUs in DEA: an improved integrated model. Comput. Ind. Eng. 52 (2007) $71-77$.

[2] P. Andersen and N. Petersen, A procedure for ranking efficient units in data envelopment analysis. Manage. Sci. 30 (1993) 1261-1264.

[3] K.D. Atalay and A. Apaydın, Şans KısıtlıStokastik Programlama Problemlerinin Deterministik Eşitlikleri. Anadolu Üniversitesi Bilim ve Teknoloji Dergisi 1 (2011) 1-18.

[4] M. Azadi and R.F. Saen, A new chance-constrained data envelopment analysis for selection third-party reverse logistics providers in the existence of dual role factors. Expert Syst. App. 38 (2011) 12231-12236.

[5] R.D. Banker, A. Charnes and W.W. Cooper, Some models for estimating tecnical and scale inefficiencies in data envelopment analysis. Manege. Sci. 30 (1984) 1078-1092.

[6] Y. Bian and F. Yang, Resource and environment efficiency analysis of provinces in Chine: a DEA approach based on Shannon's entropy. Energy Policy 38 (2010) 1909-1917.

[7] J. Borda, Memoire sur les Electin au Scrutin. Histoire de l'Academie Royale des Sciences 1781, Paris 12 (1784).

[8] J.E. Boscá, V. Liern, A. Martínez and R. Sala, Increasing offensive or defensive efficiency? An analysis of Italian and Spanish football. Omega 37 (2009) 63-78.

[9] S. Çakır and S. Perçin, AB Ülkelerinde Bütünleşik Entropi Ağırlık-Topsis Yöntemleriyle AR-GE performansının Ölçülmesi. Uludă̆ Üniversitesi İktisadi ve İdari Bilimler Fakültesi Dergisi 32 (2013) 77-95.

[10] A. Charnes and W.W. Cooper, Chance-constrained programming. Manage. Sci. 6 (1959) 73-79.

[11] A. Charnes, W. W. Cooper and E. Rhodes, Measuring the efficiency of decision making units. Eur. J.Oper. Res. 2 (1978) 429-444.

[12] X. Chen and C.-C. Lu, The impact of the macroeconomic factors in the bank efficiency: evidence from the Chinese city banks. North Am. J. Econ. Finance 55 (2020) 101294.

[13] Y. Chen, W.D. Cook, N. Li and J. Zhu, Additive efficiency decomposition in two-stage DEA. Eur. J. Oper. Res. 196 (2009) 1170-1176.

[14] A. Chitnis and O. Vaidya, Performance assessment of tennis players: application of DEA. Soc. Behav. Sci. 133 (2014) 74-83.

[15] W.D. Cook and J. Zhu, Classifying inputs and outputs in data envelopment analysis. Eur. J. Oper. Res. 180 (2007) $692-699$.

[16] W.W. Cooper H. Deng, Z. Huang and S.X. Li, Chance constrained programming approaches to congestion in stochastic data envelopment analysis. Eur. J. Oper. Res. 155 (2004) 487-501.

[17] W. Cooper, J.L. Ruiz and I. Sirvent, Selecting non-zero weights to evaluate effectiveness of basketball players with DEA. Eur. J. Oper. Res. 195 (2009) 563-574.

[18] Ö. Cosgun and G. Yurdakul, Performance evaluation of an apparel retailer's stores by using stochastic imprecise DEA. J. Mult.-Valued Logic Soft Comput. 34 (2020) 59-75.

[19] M.N. Coşkun, A.H. Çermikli, H.O. Eruygur, F. Öztürk, İ. Tokatlığlu, G. Aykaç and T. Dağlaroğlu, Türkiye'de Bankacılık Sektörü Piyasa Yapısı, Firma Davranışlarıve Rekabet Analizi. Türkiye Bankalar Birliği, İstanbul (2012).

[20] J. De Gregorio and P.E. Guidotti, Financial development and economic growth. World Dev. 23 (1995) $433-448$.

[21] E. Deliktaş and M. Balcılar, A comparative analysis of productivity growth, catch-up, and convergence in transition economies. Emerg. Markets Finance Trade 41 (2005) 6-28. 
[22] E. Demireli and A.Y. Özdemir, Seçilmiş Avrupa Ülkeleride Makroekonomik Performans Ölçümü: Şans KısıtlıVeri Zarflama Analizi ile Bir Uygulama. Dumlupınar Üniversitesi Sosyal bilimler Dergisi 37 (2013) 303-330.

[23] T. Ertay, D. Ruan and U.R. Tuzkaya, Integrating data envelopment analysis and analytic hierarchy for the facility layout design in manufacturing systems. Inf. Sci. 176 (2006) 237-262.

[24] R. Farzipoor Saen, Suppliers selection in the presence of both cardinal and ordinal data. Eur. J. Oper. Res. 183 (2007) $741-747$.

[25] D. A. Grigorian and V. Manole, Determinants of commercial bank performance in transition: An application of data envelopment analysis. Comp. Econ. Stud. 48 (2006) 497-522.

[26] P. Guo and H. Tanaka, Fuzzy DEA: a perceptual evaluation method. Fuzzy Set Syst. 119 (2001) 149-160.

[27] B. Hsiao, C.-C. Chern and C.-R. Chiu, Perdormance evaluation with entropy based weighted Russel measure in data envelopment analysis. Expert Syst. App. 38 (2011) 9965-9972.

[28] D. Ju-Long, Control Problems of Grey Systems. Syst. Control Lett. 1 (1982) 288-294.

[29] C. Kao and S.-N. Hwang, Efficiency decomposition in two-stage data envelopment analysis: an application to non-life insurance companies in Taiwan. Eur. J. Oper. Res. 185 (2008) 418-429.

[30] K. Kayalıdere and S. Kargın, Çimento ve Tekstil Sektöründe Etkinlik Çalışmasıve Veri Zarflama Analizi. Doküz Eylül Üniversitesi Sosyal Bilimler Dergisi 6 (2004) 196-219.

[31] M. Khodabakhshi, A super-efficiency model based on improved outputs in data envelopment analysis. Appl. Math. Comput. 184 (2007) 695-703.

[32] KPMG, Bankacılık: Sektörel Bakış. KPMG, İstanbul (2019).

[33] K.C. Land, C.K. Lovell and S. Thore, Chance-constrained Data Envelopment Analysis. Manage. Decis. Econ. 14 (1993) $541-554$.

[34] H.F. Lewis, K.A. Lock and T.R. Sexton, Organizational capability, efficiency, and effectiveness in Major League Baseball: 1901-2002. Eur. J. Oper. Res. 197 (2009) 731-740.

[35] J.S. Liua, L.Y. Lub and W.-M. Luc, Research fronts in data envelopment analysis. Omega 58 (2016) $33-45$.

[36] R. Mansour and C. El Moussawi, Efficiency, technical progress and productivity of Arab banks: a non-parametric approach. $Q$. Rev. Econ. Finance 75 (2020) 191-208.

[37] E.D. Mecit and İ. Alp, A new resticted model using correlation coefficients as an alternative to cross-efficiency evaluation in Data Envelopment Analysis. Hacettepe J. Math. Stat. 41 (2012) 321-335.

[38] O.B. Olesen and N.C. Petersen, Stochastic Data Envelopment Analysis: a review. Eur. J. Oper. Res. 251 (2015) 1-20.

[39] A.D. Ross, K. Kuzu and W. Li, Exploring supplier performance risk and buyer's role using chance-constraint data envelopment analysis. Eur. J. Oper. Res. 250 (2015) 1-13.

[40] A.P.S. Rubem and L.C. Brando, Multiple criteria data envelopment analysis - An application to UEFA EURO 2012. Proc. Comput. Sci. 55 (2015) 186-195.

[41] C. Şahin, B. Birdoğan, I.M. Ar, Bir Telekom Operatörünün İller Bazında Etkinliğinin Şebeke Kalitesi Açısından Değerlendirilmesi: Duyarlılık Analizi TabanlıVZA Uygulaması. Erciyes Üniversitesi İktisadi ve İdari Bilimler Fakültesi Dergisi 51 (2018) 175-197.

[42] J.-J. Shuai and W.-W. Wu, Evaluating the influence of E-marketing on hotel performance by DEA and grey entropi. Expert Syst. App. 38 (2011) 8763-8769.

[43] M. Soleimani-Damaneh and M. Zarepisheh, Shannon's entropy for combining the efficiency results of different DEA models: Method and Application. Expert Syst. App. 36 (2009) 5146-5150.

[44] T. Sueyoshi, Stochastic DEA for restructure strategy: an application to a japanese petroleum company. Omega 28 (2000) 385-398.

[45] S. Talluri and K.P. Yoon, A cone-ratio DEA approcah for AMT justification. Int. J. Prod. Econ. 66 (2000) $119-129$.

[46] S. Talluri, R. Narasimhan and A. Nair, Vendor performance with supply risk: a Chance-constrained DEA approch. Int. J. Prod. Econ. 100 (2006) 212-222.

[47] M. Toloo, Alternative solutions for classifying inputs and outputs in data envelopment analysis. Comput. Math. App. 63 (2012) 1104-1110.

[48] M. Toloo and S. Nalchigar, A new DEA method for supplier selection in presence of both cardinal and ordinal data. Expert Syst. App. 38 (2011) 14726-14731.

[49] M. Toloo, M. Allahyar and J. Hančlová, A non-radial directional distance method on classifying inputs and outputs in DEA: application to banking industry. Expert Syst. App. 92 (2018) 495-506.

[50] M. Toloo, E. Keshavarz and A. Hatami-Marbini, Dual-role factors for imprecise data envelopment analysis. Omega 77 (2018) $15-31$.

[51] H. Tunca and E. Deliktaş, OECD Ülkelerinde Tarımsal Etkinlik Ölçümü: Dinamik Veri Zarflama Analizi. Ege Akademik Bakış 15 (2015) 217-227.

[52] A. Wadud and B. White, Farm household efficiency in Bangladesh: a comparison of stochastic frontier and DEA methods. Appl. Econ. 32 (2000) 1665-1673.

[53] Y.M. Wang, J. Liu and T.M.S. Elhag, An integrated AHP-DEA methodology for bridge risk assessment. Comput. Ind. Eng. 54 (2008) 513-525.

[54] W.W. Wei, An integrated solution for benchmarking using DEA, gray entropy, and Borda count. Serv. Ind. J. 32 (2012) $321-335$. 
[55] K.-L. Wen, T.-C. Chang and M.-L. You, The grey entropy and its application in weighting analysis. IEEE 2 (1998) $1842-1844$.

[56] W.-W. Wu, Beyond travel \& tourism competitiveness ranking using DEA, GST, ANN and Borda Count. Expert Syst. App. 38 (2011) 12974-12982.

[57] J. Wu, J. Sun, L. Liang and Y. Zha, Determination of weights for ultimate cross efficiency using Shannon's entropy. Expert Syst. App. 38 (2011) 5162-5165.

[58] M. Yuttadur and K. Bulut, Türkiye'de Bankacılık Sektörünün Finansal Yapısıve Bu Yapının Müşteri Tercihlerine Etkisi. İstanbul (2015).

[59] M. Zeydan and C. Çolpan, A new decision support system for performance measurement using combined fuzzy Topsis/DEA approach. Comput. Ind. Eng. 47 (2008) 513-525.

[60] H. Zhang, C. Gu, L. Gu and Y. Zhang, Evaluation of tourism destination competitiveness bt topsis \& information entropy E. A case in the Yangtze River Dealta Of China. Tourism Manage. 322 (2011) 443-451. 